\title{
Evaluation of Fire Evacuation Performance of Building Atriums based on Decision Support System
}

\author{
Weidong $\mathrm{Wu}^{\mathrm{a}}$, Bohao $\mathrm{Xu}^{\mathrm{a}, *}$, Qinwen Tan ${ }^{\mathrm{a}}$, Chuxuan Ren ${ }^{\mathrm{b}}$, and Tangqiao Gou ${ }^{\mathrm{a}}$ \\ ${ }^{a}$ School of Civil Engineering and Architecture, Southwest Petroleum University, Chengdu, 610500, China \\ ${ }^{b}$ School of Management, Sichuan University of Science and Engineering, Yibin, 644000, China
}

\begin{abstract}
In this paper, a decision support system (DSS) of model, data, and human-computer interaction is established to evaluate the fire evacuation performance of atriums. Firstly, based on a large amount of literature and consultation with relevant scholars and experts, this paper established an indicator system for the influencing factors of fire evacuation in building atriums. Secondly, this paper used the entropy weight method model and the comprehensive rating model as the core of the model library to calculate the weight of each level indicator system and complete the evaluation work. Then, the back-end database of the data components established by Access (including the basic database, algorithm database, and expert database) was used to store the data tables and data files generated in the system work. Finally, based on the relevant literature and norms, a scientific indicator scoring standard was established. By inputting the indicator score of the evaluated object into the DSS, the final evaluation result was obtained. At the end of this paper, a large shopping center was used as a case study. The DSS was awarded a medium fire evacuation level with a score of 78.1. In order to improve its fire evacuation capability, the DSS gave corresponding decision suggestions.
\end{abstract}

Keywords: decision support system (DSS); building atrium; evaluation of fire evacuation performance; fire evacuation

(Submitted on March 20, 2019; Revised on April 2, 2019; Accepted on June 6, 2019)

(C) 2019 Totem Publisher, Inc. All rights reserved.

\section{Introduction}

In recent years, with the acceleration of China's modernization and urbanization, architectural forms with atriums have begun to prevail in complex buildings such as large space buildings and super high-rise buildings. However, for the evaluation of fire evacuation performance of building atriums, China has not yet formed specific regulations and relevant policies. Meanwhile, due to the unique characteristics of the building atrium, the conventional evaluation methods are ineffective for it [1]. Therefore, it is of urgent practical significance to establish a new evaluation method to provide decision-makers with effective decision-making information.

At present, in the study of applying DSS to specific fire evacuation scenarios, most scholars have chosen two approaches. The first is to combine the geographic information system (GIS) with DSS. Wu combined the alternative methods of spatial with GIS to construct a large-scale shopping mall and its surrounding emergency evacuation process simulation system [2]. Wen realized the integration of GIS and urban emergency evacuation key models and finally established a city emergency evacuation prototype system [3]. Using GIS as a technology platform, Zhou integrated intelligent decision-making techniques into it and established a system of urban fire protection planning support methods [4]. Jiang et al. established an emergency evacuation platform based on mobile GIS, which can simulate the dynamic path of evacuation inside buildings and solve the problem of emergency evacuation in complex buildings. The second approach is to establish an agent-based DSS for fire evacuation and human behavior research [5]. Wagner et al. proposed an agent-based simulation system to simulate evacuation of people in fires in large venues such as opera houses, stadiums, and auditoriums [6]. Manley et al. established an agent-based DSS to analyze the evacuation behavior of disabled people in different emergency situations [7]. Balakhontceva et al. established a multi-agent simulation system to simulate the passenger evacuation process in the event of a ship emergency [8]. Du et al. proposed an agent-based behavioral decision-making

* Corresponding author.

E-mail address: xubohao1995@qq.com 
model, which mainly considers the fire scenario and the comprehensive emotions of people in the scenario, and it can analyze and accurately simulate the group behavior of fire escapes at low cost [9]. In addition to the above two approaches, some scholars have established different DSS based on other methods, but their research purposes are also to solve or simulate similar risk issues such as evacuation in specific fire scenarios. Kochilkis et al. established a web-based DSS that primarily implements fire control and planning for forests and risk management of floods [10]. Pribyl et al. established a new practical road tunnel risk analysis system that reduces the cost of the tunnel safety system [11]. Shahparvari et al. established a DSS to guide vehicle evacuation routes, select shelters, and allocate vehicles in the event of a sudden forest fire [12]. Sarshar et al. proposed a dynamic Bayesian network simulation model to analyze congestion during ship evacuations in the case of a sudden fire. In the field of building fire risk assessment and fire evacuation performance evaluation, domestic and foreign scholars have also achieved good scientific research results [13]. Shi et al. began with the actual engineering case and analyzed the fire protection design requirements and safety evacuation concepts of commercial complexes [14]. Wang used the grey relational analysis method to construct a grey relational analysis and evaluation model for high-rise building fire systems, and it was used to evaluate the fire risk level of high-rise buildings [15]. In order to assess the risk of fire in colleges and universities, Du first classified the university buildings according to their functions and then established a three-level indicator evaluation system for each classification. He then calculated the weights of each evaluation indicator using the entropy method. Finally, based on Matlab and VB technology, the university building fire risk assessment system was developed [16]. Chen used the fault tree analysis (FTA) method to quantitatively evaluate subway fire risks [17]. Wu et al. used the analytic hierarchy process (AHP) and model builder tools to complete the quantitative assessment of fire risks and solve the fire hazard problem in historical and cultural blocks [18]. Feng relied on set pair analysis to conduct a comprehensive evaluation of the fire risk assessment of construction in progress [19].

It can be seen from the above research results that although many scholars have applied DSS to the simulation and evacuation of specific fire scenes, most of the research focuses only on the field of process control and subsequent control of fire. Although the theoretical results of building fire risk assessment promote and develop the research in the field of fire pre-control, it is impossible to provide effective decision-making information to decision makers quickly and directly. This is due to the complexity and abstraction of the evaluation process, as well as the fact that few are combined with computer science through DSS or other similar approaches. Therefore, the research on combining DSS with building fire risk assessment is still not deep enough; in particular, the research on DSS applications in the evaluation of fire evacuation performance of building atriums is unexplored. Therefore, in the face of this urgent problem that needs to be solved, the DSS established in this paper needs to achieve the following research goals: first, according to the important influencing factors of fire evacuation in building atriums, it is necessary to establish a set of evaluation indicators system suitable for evaluation of fire evacuation performance of building atriums. Second, with reference to relevant industry norms and relevant experience of experts and scholars, develop a set of scientific indicators scoring evaluation criteria, and complete the conversion of indicators from qualitative to quantitative. Third, it is necessary to establish a DSS that can automatically and scientifically evaluate the fire evacuation performance of building atriums and provide targeted decision-making recommendations.

\section{Establishment of Indicator System for Influencing Factors of Fire Evacuation in Building Atriums}

The selection of the factors affecting the fire evacuation of building atriums needs to be consistent with the systemic characteristics. The design of the indicators needs to cover all the influencing factors of fire evacuation. Therefore, based on relevant literature [20-25], this paper refers to the relevant building code [26] after consulting relevant scholars, industry experts, and practitioners in building fire protection and initially sorting out the influencing factors of fire evacuation in building atriums. In order to make the indicator system reflect the actual situation objectively, the selection of influencing factors follows the principles of qualitative and quantitative. At the same time, considering the hierarchical nature of the indicator system, this paper initially divides the indicator system into two levels and maintains independent support relationships. In order to prevent deviations in evaluation results caused by information duplication, the indicators are refined. After completing the above work, this paper initially established an indicator system for the influencing factors of fire evacuation in building atriums, including 33 first-level indicators and 37 second-level indicators.

However, the initially established indicator system has a large degree of subjectivity. Therefore, the authors used a questionnaire survey to screen and determine the influencing factors to enhance their rationality and scientificity. The questionnaire survey was mainly disseminated to ordinary people, industry experts, and scholars through online channels, postal mail, telephone, and on-site consultation. This paper uses the Likert scale method to measure whether the indicators can accurately and reasonably reflect the degree of fire evacuation performance of building atriums. The indicators are divided into five grades according to the importance degree; 1 to 5 points represent unimportant, less important, generally important, important, and very important, respectively. There were 200 questionnaires distributed, and 180 copies were available. 
In order to determine the final indicator system and ensure its scientificity, objectivity, and comprehensiveness, this paper uses IBM SPSS Statistics to complete the reliability and validity analysis of the questionnaire.

\subsection{Questionnaire Reliability Analysis}

This paper selects the internal consistency reliability detection method to analyze the questionnaire and uses Cronbach's $\alpha$ coefficient as the measurement standard. The magnitude of Cronbach's $\alpha$ coefficient reflects the reliability of the questionnaire. It is generally believed that Cronbach's $\alpha$ coefficient is above 0.80 , which has a high level of reliability. If it is less than 0.6 , the content of the questionnaire needs to be appropriately adjusted to improve its reliability level [27]. After analyzing the data of 180 questionnaires, the overall Cronbach's $\alpha$ coefficient of the questionnaire is $0.878>0.8$, which indicates that the internal consistency is high and the reliability of the questionnaire meets the requirements. In order to further improve the overall reliability, this paper continues to deal with the indicators. After deleting each indicator and then calculating the Cronbach's $\alpha$ coefficient of the questionnaire, it was found that the overall reliability of the questionnaire was increased to 0.883 after deleting the indicator of "atrium roof shape", so the authors decided to delete it.

\subsection{Questionnaire Validity Analysis}

In terms of validity analysis, this paper focuses on the analysis of structural validity, because structural validity can prove whether the indicators in the questionnaire are consistent with the assumptions of scientific theory [28]. The method used is the factor analysis method. In order to analyze whether the questionnaire is suitable for this method, Kaiser-Meyer-Olkin (KMO) analysis and Bartlett's test are performed on the variables in the questionnaire. After calculation, the KMO value is $0.738>0.5$, indicating that the factor analysis method can be used, and the significance value is $0.000<0.01$, indicating that there is a strong correlation between the variables of the questionnaire.

Then, this paper uses IBM SPSS Statistics to analyze the constants of the questionnaire and obtain the common factor variance of the indicator system. The initial variance of all the indicators is 1 , indicating that the initial indicators can be explained; in addition, the commonality of each data constant is greater than 0.4 and mainly concentrated around 0.8 , which shows that the common factor can represent the information of the questionnaire from various aspects.

Next, the maximum variance method is used to extract the common factors. The factor contribution rate data obtained from IBM SPSS Statistics shows that all 32 indicators in the initial eigenvalue part are extracted, the initial variables of the indicators are all explained, and all the indicators have corresponding contributions. At the same time, the system extracted four common factors. The cumulative total variance and the cumulative total variance after rotation were $66.347 \%$, indicating that the extracted common factors can have effective response scale information.

Since only four factors are needed to express the whole information, the principal component analysis method is used, and the exploratory factor analysis of the questionnaire is performed by using the maximum variance method of correlation matrix rotation. Data less than 0.6 are deleted during the software statistics process. After analyzing the final results, the authors found that the common factor 1 contains 11 high-associated indicators such as "type of atrium" (specific indicators can be seen in Table 1), which are all related to the characteristics of the atrium or the influencing factors between the atrium and the building in which it is located, so the common factor 1 is named "building factor". In the same way, the other three common factors are named "environmental factors", "personnel factors", and "fire prevention equipment factors".

\subsection{Final Establishment of the Indicator System}

Through the analysis and processing of the above steps, the indicator system for influencing factors of fire evacuation in building atriums is finally obtained. In the final indicator system, the above four common factors are used as the first-level indicators, and the first-level indicators and the second-level indicators in the initial indicator system are changed to the second-level indicators and the third-level indicators, as shown in Table 1.

\section{The Overall Design of DSS of Evaluation of Fire Evacuation Performance of Building Atriums}

DSS is a dynamic interactive computer system that supports managers when making judgments, improves the effectiveness of decisions, and accepts the direct judgment and experience of decision makers. It is used to support semi-structured and unstructured decision making. This concept was first proposed by Mckenney et al. [29] in the 1970s. In the following decades, with the advancement of decision theory, management science, information technology, artificial intelligence, expert systems, knowledge engineering, computer technology, and communication methods, DSS has grown tremendously and has become one of the fastest growing research branches in the field of information and decision science [30-34]. 
Table 1. The indicator system for influencing factors of fire evacuation in building atriums

\begin{tabular}{|c|c|c|c|c|c|}
\hline First-level indicators & Weight & Second-level indicators & Weight & Third-level indicators & Weight \\
\hline \multirow{16}{*}{ Building factors } & \multirow{16}{*}{0.295} & Type of atrium & 0.044 & & \\
\hline & & Plane position of the atrium in the building & 0.047 & & \\
\hline & & $\begin{array}{l}\text { Relationship between the atrium and the } \\
\text { floor }\end{array}$ & 0.054 & & \\
\hline & & $\begin{array}{l}\text { Relationship between the top of the atrium } \\
\text { and the building as a whole }\end{array}$ & 0.051 & & \\
\hline & & Plane shape of the atrium & 0.044 & & \\
\hline & & Atrium area & 0.058 & & \\
\hline & & Height of the atrium & 0.054 & & \\
\hline & & Spatial connectivity of the atrium & 0.075 & & \\
\hline & & \multirow{3}{*}{ Fire resistance and load of buildings } & \multirow{3}{*}{0.339} & Unit area load & 0.328 \\
\hline & & & & Fire-resistant level & 0.340 \\
\hline & & & & $\begin{array}{c}\text { Combustion characteristics of } \\
\text { decoration materials }\end{array}$ & 0.332 \\
\hline & & \multirow{3}{*}{ Fire zone } & \multirow{3}{*}{0.153} & Vertical fire zone & 0.332 \\
\hline & & & & Horizontal fire zone & 0.336 \\
\hline & & & & Fire separation of important parts & 0.332 \\
\hline & & \multirow[t]{2}{*}{ Electrical equipment } & \multirow[t]{2}{*}{0.081} & $\begin{array}{c}\text { Transmission and distribution lines and } \\
\text { power facilities }\end{array}$ & 0.516 \\
\hline & & & & Fire power supply and its distribution & 0.484 \\
\hline \multirow{7}{*}{ Environmental factors } & \multirow{7}{*}{0.130} & \multirow{2}{*}{ Fire characteristics } & \multirow{2}{*}{0.231} & Fire source location & 0.500 \\
\hline & & & & Source power / Flame intensity & 0.500 \\
\hline & & \multirow{3}{*}{ Smoke factor in fire } & & Thermal radiation from fire smoke & 0.356 \\
\hline & & & 0.462 & Light reduction of fire smoke & 0.324 \\
\hline & & & 0.402 & $\begin{array}{l}\text { The harm of poisonous gas to human } \\
\text { body }\end{array}$ & 0.320 \\
\hline & & Fire separation & 0.162 & & \\
\hline & & Outdoor fire hydrant system & 0.146 & & \\
\hline \multirow{18}{*}{ Personnel factors } & \multirow{18}{*}{0.194} & \multirow{5}{*}{ Physiological factors } & \multirow{5}{*}{0.093} & Gender & 0.154 \\
\hline & & & & Age & 0.209 \\
\hline & & & & Physical conditions & 0.209 \\
\hline & & & & Degree of education & 0.212 \\
\hline & & & & Fire experience & 0.215 \\
\hline & & Psychological factors & 0.088 & & \\
\hline & & Human escape behavior & 0.093 & & \\
\hline & & & & $\begin{array}{l}\text { Establishment and implementation of } \\
\text { the fire protection system }\end{array}$ & 0.166 \\
\hline & & & & Management and maintenance level & 0.164 \\
\hline & & Safety management level & & Fire education training & 0.164 \\
\hline & & sarety management rever & 0.203 & $\begin{array}{l}\text { Security guide } \\
\end{array}$ & 0.161 \\
\hline & & & & $\begin{array}{c}\text { Fire safety awareness of personnel in } \\
\text { buildings }\end{array}$ & 0.177 \\
\hline & & & & Emergency Rescue & 0.168 \\
\hline & & Familiarity with evacuation routes & 0.103 & & \\
\hline & & Evacuation method and path & 0.124 & & \\
\hline & & & & Personnel density & 0.331 \\
\hline & & Cluster factor of people flow & 0.237 & Flow coefficient of entrance and exit & 0.331 \\
\hline & & & & Cluster migration flow rate & 0.339 \\
\hline & & Fire detecting system & 0.084 & & \\
\hline & & Fire alarm system & 0.092 & & \\
\hline & & Fire extinguishing system & 0.113 & Automatic sprinkler system & 0.519 \\
\hline & & 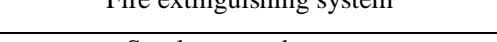 & & Indoor fire hydrant system & 0.481 \\
\hline & & Smoke control system & 0.123 & & \\
\hline & & Fire rescue facility & 0058 & Fire lift & 0.513 \\
\hline & & 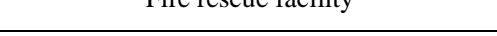 & 0.050 & Fire lanes & 0.488 \\
\hline & & & & Fire accident light & 0.500 \\
\hline equipment system & 0.381 & Emergency lighting system & 0.052 & $\begin{array}{c}\text { Fire accident evacuation instruction } \\
\text { lighting } \\
\end{array}$ & 0.500 \\
\hline & & Evacuation indication & 0.115 & & \\
\hline & & Exit distance & 0.157 & & \\
\hline & & & & Evacuation channel length & 0.252 \\
\hline & & Safe evacuation channel & 0.118 & $\begin{array}{l}\text { Effective width of the evacuation } \\
\text { channel }\end{array}$ & 0.252 \\
\hline & & & & Entrance width & 0.245 \\
\hline & & & & Channel patency & 0.252 \\
\hline & & Emergency exit & 0.087 & & \\
\hline
\end{tabular}


The DSS designed in this paper adopts the basic structure of three parts: dialogue (human-computer interaction) [35], model, and data. The design content of each part is as follows:

- The contents of the data component mainly include: basic database (including data for first-level, second-level, and third-level indicators), expert database (including first-level, second-level, and third-level indicators score data), algorithm database (including entropy weight analysis results and comprehensive rating analysis results).

- The contents of the model component mainly include: entropy weight method model (calculation model for indicator weights at all levels) and comprehensive rating model.

- Human-computer interaction is mainly realized by the human-machine dialogue window, which is the console of the whole DSS. Its main functions include user information entry and login, search and analysis of relevant data in the database, running of models in the model library, and output of system information.

\subsection{Data Component}

The data component of the system is mainly composed of three major databases: basic database, expert database, and algorithm database. Ten data tables are created through an open database connection to store the information contained in the three databases. The data standards are all based on Chinese national standards.

The basic database contains the first-level, second-level, and third-level indicators data. The main function is to store the basic attribute data of each level of indicators and collect and record the indicator scores. The corresponding attribute data is stored in the data table index 1 , index 2 , and index 3 , the field type is numeric, and the field length is 10 bytes and 20 bytes. Table 2 shows the attribute data of the data table index 1 .

Table 2. The Storage structure of attribute data of first-level indicators (index1)

\begin{tabular}{|c|c|c|c|}
\hline Indicator field name & Indicator field description & Indicator field type & Indicator field length \\
\hline JZW & Building factors & numeric & 10 bytes \\
\hline HJ & Environmental factors & numeric & 10 bytes \\
\hline RY & Personnel factors & numeric & 10 bytes \\
\hline FHSBXT & Fire protection equipment system factors & numeric & 10 bytes \\
\hline
\end{tabular}

This paper adopts the five-level Likert-type scale method to formulate "The questionnaire on the weight distribution of influencing factors of fire evacuation in building atrium", and it invites ten authoritative experts and scholars in the field of building fire evacuation. Experts score the importance of each indicator based on their professional knowledge and experience. The expert database stores the score data of all levels of indicators. The names of the indicator data storage structure tables are expert1, expert2, and expert3, and each indicator has ten scores. Because the data contained in the expert database is too large, it will not be shown in detail in this paper.

The algorithm database consists of the results of entropy weight analysis and comprehensive rating analysis. The data tables of entropy weight analysis results are entropy1, entropy2, and entropy3, and the field type is also numeric, with a field length of 10 bytes. Table 3 shows part of the data table entropy3. The comprehensive rating analysis table name is ove_rank, the field type is a character, and the field length is 8 bytes, as shown in Table 4.

Table 3. The storage structure of attribute data of entropy weight method analysis results (III) (entropy3)

\begin{tabular}{|c|c|c|c|}
\hline Indicator field name & Indicator field description & Indicator field type & Indicator field length \\
\hline DMHQZ & Unit area load & numeric & 10 bytes \\
\hline JNDQZ & Fire-resistant level & numeric & 10 bytes \\
\hline CRTQZ & Combustion characteristics of decoration materials & numeric & 10 bytes \\
\hline ZFFQZ & Vertical fire zone & numeric & 10 bytes \\
\hline
\end{tabular}

Table 4. The storage structure of attribute data of Comprehensive rating analysis results (ove_rank)

\begin{tabular}{|c|c|c|c|}
\hline Indicator field name & Indicator field description & Indicator field type & Indicator field length \\
\hline DJ & Evaluation of fire evacuation performance of building atrium & character & 8 bytes \\
\hline
\end{tabular}

\subsection{Model Component}

\subsubsection{Research Method for Determining Indicator Weights}

In order to be able to scientifically and objectively determine the weight of indicators at all levels, the research method adopted in this paper is the entropy weight method. Based on the scoring data of ten experts mentioned above on each indicator, the weight of each indicator is calculated. As a method to determine weight, the entropy weight method has the 
same principle as the weight assignment method in information theory. In the entropy weight method, the weight coefficient is determined by measuring how much effective information the indicator can provide to the decision maker. The operation steps of the entropy weight method are as follows:

First, construct a matrix containing the number of indicators $m$, and the number of objects to be evaluated is $n$. The initial evaluation matrix is:

$$
X=\left[\begin{array}{cccc}
X_{11} & X_{12} & \ldots & X_{1 n} \\
X_{21} & X_{22} & \ldots & X_{2 n} \\
\vdots & \vdots & \vdots & \vdots \\
X_{m 1} & X_{m 2} & \ldots & X_{m n}
\end{array}\right]
$$

Next, the above matrix is transformed into a normalized direction to obtain a normalized matrix $Y_{m n}$. The standardized processing method used by the author in this process is the extreme value processing method, as shown in Equation (1):

$$
Y_{i j}=\frac{x_{i j}-m_{j}}{M_{j}-m_{j}}
$$

Where $M_{j}=\max \left\{x_{i j}\right\}$ ( $i$ fixed) and $m_{j}=\min \left\{x_{i j}\right\}$ ( $i$ fixed).

The entropy value of the item $\mathrm{j}$ indicator can be obtained by the calculation of Equation (2):

$$
H_{j}=-\mathrm{a} \sum_{i=1}^{n} L_{i j} \ln \mathrm{L}_{i j}, i=1,2, \cdots, m
$$

Where $a=1 / \ln n$ and $L_{i j}=Y_{i j} / \sum_{i=1}^{n} Y_{i j}$. When $L_{i j}=0, \lim _{L_{i j} \rightarrow 0} L_{i j} \ln L_{i j}=0$.

After the above results are obtained, the entropy weight of the item $j$ indicator can be known by calculating according to Equation (3):

$$
W_{j}=\frac{1-H_{j}}{m-\sum_{j=1}^{m} H_{j}}, j=1,2, \cdots, m
$$

Where $0 \leq W_{j} \leq 1$ and $\sum_{j=1}^{m} W_{j}=1[36]$

\subsubsection{Model File Library}

The model file library stores various files used by the model in the form of files, including source files, object files, description files, and information files. Each mathematical model of the system corresponds to a source program file, an executable program file, a model description file, an input parameter table, and an output parameter table. The documents and their descriptions are as follows:

- Source program file: source code generation file for the corresponding model developed with the C++ programming language.

- Executable program file: the files generated after editing the source program can be invoked directly in the Microsoft Visual C++.

- Model description file: a description document containing the relevant mathematical description, functional application, program development, and usability of the model.

- Input parameter table: a table containing all the input parameters of the model.

- Output parameter table: a table containing all the output parameters of the model.

This paper only describes the source code of the source file of the entropy weight method in detail, as shown in Table 5, and the DSS stores the weights of the indicators at all levels calculated by the entropy weight method in the data tables entropy1, entropy2, and entropy3. The detailed indicator weight values are shown in Table 1. 
Table 5. Entropy weight method source code

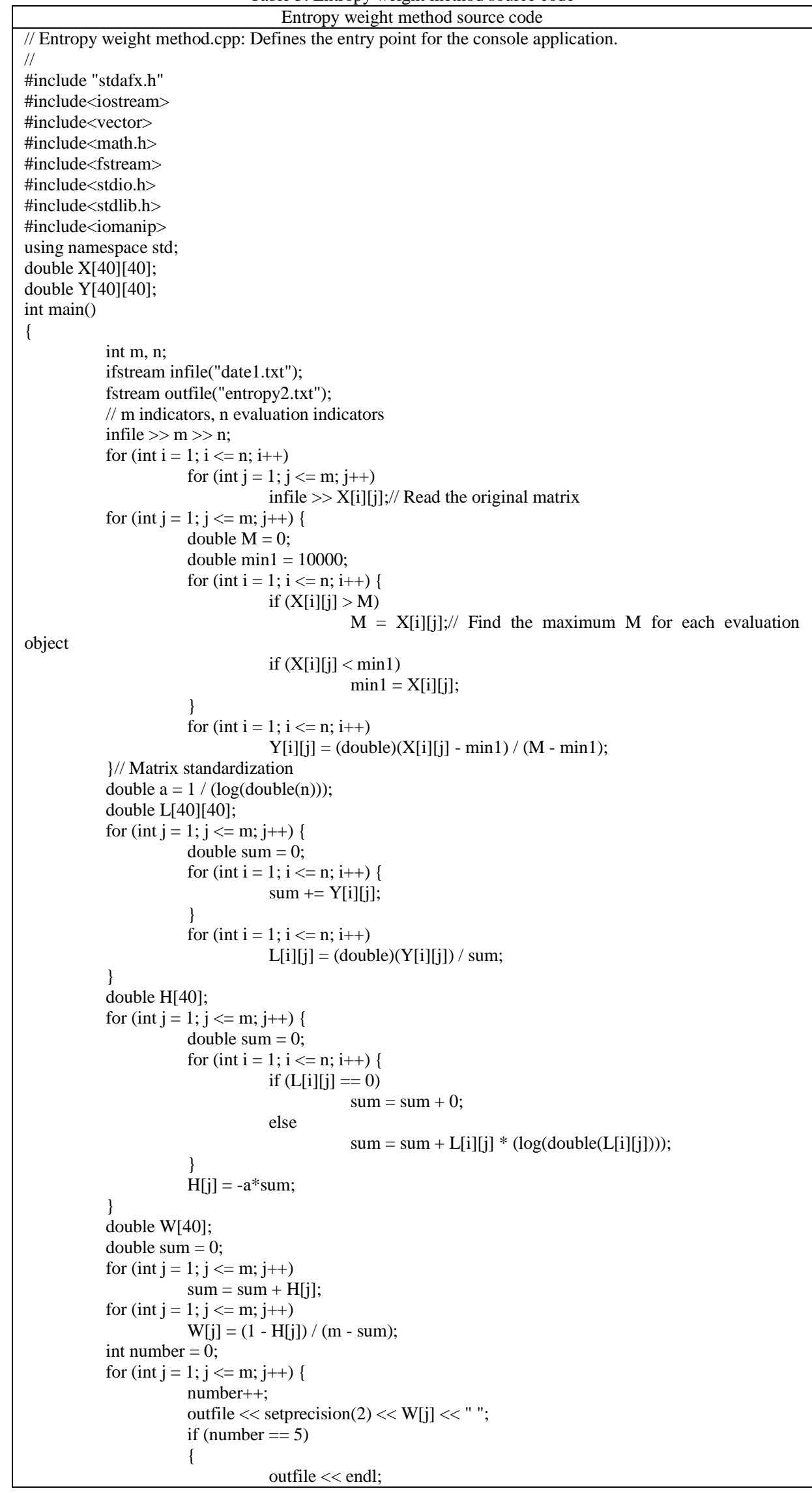




\begin{tabular}{|c|c|}
\hline & number $=0$; \\
return 0; & \\
\hline
\end{tabular}

\subsection{Human-Computer Interaction Component}

Enter the user name and password in the login screen of the DSS of evaluation of fire evacuation performance of building atriums to enter the system main interface. It can be seen from the main interface that the software mainly includes the following modules: data entry, data query, and data modification under the database part; the model evaluation module under the model library part; and the user management module under the human-computer interaction part.

In the data entry module, there are two subordinate options: second-level indicators and third-level indicators. Click the different subordinate options to enter the indicator entry interface, and then enter the values of the various indicators of the evaluation object. The data query module includes two subordinate options: basic data and expert data, which store the indicator data of each level and the expert score data of each level of indicators; the module can query the detailed data such as the storage address and value of each indicator. The data modification module includes two subordinate options: data change and data deletion, the indicator data can be modified and deleted by clicking different subordinate options. The function of the two subordinate options under the model evaluation module is to calculate the weight value of each indicator and obtain the final comprehensive rating result after the first and second level indicators information data of the evaluation object are successfully entered, and the specific operation process will be explained in detail in the following cases. The user management module mainly has functions such as user addition, user deletion, user modification, and user logout, and it is implemented by function keys such as logout and addition.

\subsection{DSS Management System}

DSS management system is the premise that the database and model library can run normally. It is firstly used as the data support platform of the database, which is intended to realize the management and maintenance of adding, deleting, modifying, and querying related data.

Secondly, the storage management of the model refers to the management of the review, maintenance, invocation, and modification of the model file. The organizational structure used in model storage in this paper is mainly comprised of two parts: model dictionary library and model file library; the former stores the file name and code name of all models, and the latter is primarily used to store the body content of the model. The user can query and retrieve the model file through the path specified by the model dictionary library. At the same time, the stored model can be modified and replaced, and a new model can be inserted as needed to realize the storage management of the entire model.

The operation management of the model is mainly realized through three aspects: first, the input and compilation of the model program is realized by writing the source code in Microsoft Visual C++; second, the running control of the model is realized by running the target program of the model in the DSS master control program; and third, the data interface is established to complete the model library and the database, and the data required by the model runtime and the generated data are linked with the database, thereby realizing the model to access the data.

The entropy weight method model can only use the expert scoring data to calculate the weight of each level of indicators. In order to achieve the assessment of fire evacuation performance of the assessment object, DSS needs to use the comprehensive rating model to combine the scores of the indicators at each level with the weights of the indicators calculated by the entropy method. Therefore, the comprehensive rating model cannot work alone. It needs to be combined with the entropy weight method model to ensure the normal operation of the system. The model base management system itself is not directly involved in the model combination process but achieves data transmission and sharing between each sub model in order to complete their respective data processing work and improve the performance of the portfolio model and the implementation model of portfolio management.

\section{Case Study}

In order to verify the scientific and effective of DSS of evaluation of fire evacuation performance of building atriums, this paper chooses a four-story shopping mall as a case study. The building is a comprehensive commercial building with a maximum height of 32.5 meters, a main roof height of 22.5 meters, a total construction area of 150813 square meters, and a total land area of 71919 square meters. The building plane is a two-wing structure connected by a large atrium structure in the 
middle. There are several atriums in the north and southeast commercial areas of the building and in the middle of the two areas. The height of the central atrium is 32.5 meters, and the height of the inner atrium of the two wings is 22.5 meters [37].

\subsection{Determination of Indicator Score}

In order to complete the entry of the indicators data of the large shopping center, it is first necessary to determine the score of each indicator. However, there is currently no authoritative reference to the indicator for influencing factors of fire evacuation in building atriums. Therefore, according to the research results of existing scholars and the relevant legal norms in China, the authors have made provisions on the value standards of the indicators involved in this paper. Each indicator has a full score of 100 points. For example, for the "fire-resistant level" in the third-level indicator, the score is 90 to 100 points for the first level, 80 to 89 points for the second level, 70 to 79 points for the third level, and 60 to 69 points for the fourth level. The rest of the indicators have similar scientific scoring standards. Since the content of the scoring standards and the final score data is too large, this paper only shows part of it in Table 6.

Table 6. Scoring standard and score of indicators (partial)

\begin{tabular}{|c|c|c|c|}
\hline $\begin{array}{c}\text { Indicator } \\
\text { level }\end{array}$ & Indicator name & Scoring standard & Score \\
\hline III & Unit area load & $\begin{array}{l}\text { Greater than or equal to } 5 \mathrm{KN} / \mathrm{m}^{2} \text { is } 90-100,4-5 \mathrm{KN} / \mathrm{m}^{2} \text { is } 80-89,3-4 \mathrm{KN} / \mathrm{m}^{2} \text { is } 70-79,2-3 \mathrm{KN} / \mathrm{m}^{2} \text { is } 60 \text { - } \\
69 \text {, less than } 2 \mathrm{KN} / \mathrm{m}^{2} \text { is less than } 60 .\end{array}$ & 85 \\
\hline III & Fire-resistant level & The first level is 90-100; the second level is $80-89$; the third level is $70-79$; the fourth level is $60-69$. & 95 \\
\hline II & Type of atrium & The concentrated placement score is below 75, and the scattered walkway score is above 75. & 70 \\
\hline II & $\begin{array}{l}\text { Plane shape of the } \\
\text { atrium }\end{array}$ & $\begin{array}{l}\text { In the central level of the building, the score is } 75 \text { or less; on the side of the building or the entrance } \\
\text { score is } 75 \text { and above. }\end{array}$ & 69 \\
\hline
\end{tabular}

\subsection{Specific Application of DSS in the Case}

After determining the score for each indicator, the score data needs to be entered into the basic database in the DSS. After entering the main page of the system, click the second-level indicators and the third-level indicators option under the data entry module to record the specific score data into the system one by one. Figure 1 shows the process of entering secondlevel indicators.

After completing the score data entry, the system automatically calls the third-level indicators expert scoring data from the expert database and calls the entropy weight method model from the model library. Then, it calculates the third-level indicators weight value, and finally the weight value of each indicator is stored in the entropy method analysis result table entropy 3 in the algorithm database for management. Click the entropy weight method button under the model evaluation module to obtain the final evaluation result, as shown in Figure 2. Next, the comprehensive rating model will call the scores of the third-level indicators that have been successfully entered in the basic database and call the analysis result of entropy weight method in the entropy 3 table. Finally, it will calculate the scores of the second-level indicators with the third-level indicators. These score values will be stored in the second-level indicators data table index 2 in the basic database, and the second-level indicators score data without the third-level indicators originally entered constitutes a complete second-level indicators data table.

Then, the system continues to call the second-level indicators expert scoring data from the expert database, calls the entropy weight method model from the model library, and calculates the second-level indicators weight values, which are stored in the entropy method analysis result table entropy 2 for management. Click the entropy weight method button under the model evaluation module to get the final evaluation result, as shown in Figure 3. Next, the comprehensive rating model will call the data in the second-level indicators data table index 2 in the basic database, call the entropy weight method analysis result in the entropy 2 table, and store the obtained data in the first-level indicators data table index 1 in the basic database.

Finally, the system also calls the expert first-level indicators score data from the expert database and calls the entropy weight method analysis model from the model library to calculate the first-level indicators weight values, which are stored in the entropy method analysis result table entropy1 for management. The evaluation results are also shown in Figure 3. Then, the comprehensive rating model will call the score of the first-level indicator data table index 1 and the entropy-weight analysis result table entropy1 to calculate the current status of the building atrium fire evacuation, and it will rank the level. This paper uses the percentage system score; according to the standards, 90 points and above is excellent, 80-90 is good, 7080 is medium, 60-70 is qualified, and 60 points or less is unqualified.

Through the above series of work, DSS finally obtained the evaluation results of the large shopping center atrium and 
put forward suggestions and improvement measures. The results are shown in Figure 4. It can be seen that the score of this atrium is 78.1; the grade is medium. Although it has basic fire evacuation capability, there are still certain safety hazards, so DSS gives the following suggestions: first, set up mechanical smoke exhaust facilities; second, add fire elevators; third, improve fire lanes; and fourth, strengthen safety management. After a retrospective analysis of the indicator scores of the atrium of the large shopping mall, it was found that "fire protection equipment system factors" was the indicator with the highest weight value among the first-level indicators. The scores of "smoke control system " and "fire rescue facilities" of the two second-level indicators were only 59.000 and 67.313 respectively, so the DSS gave the first three suggestions. Although the weight value of "personnel factor" in the first-level indicators was not high, the weight of its subordinate second-level indicators "safety management level" was the highest. The score of this indicator was only 76.717, so DSS gave the fourth suggestion.

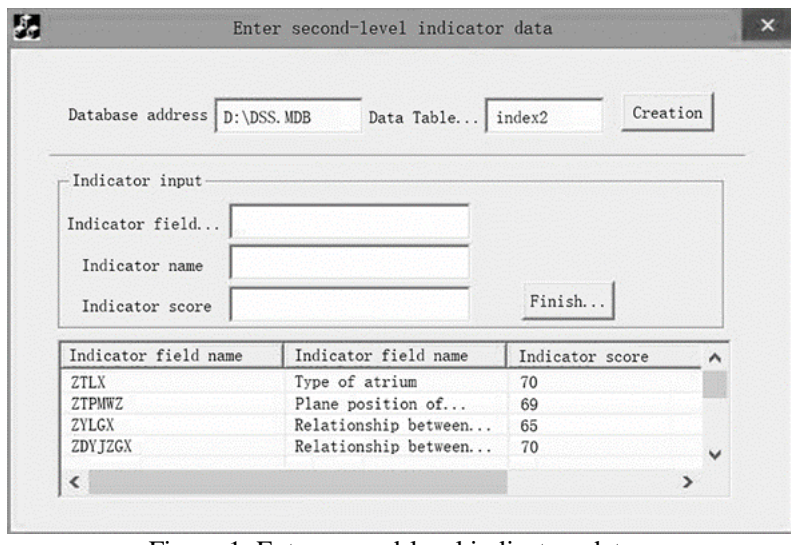

Figure 1. Enter second-level indicators data

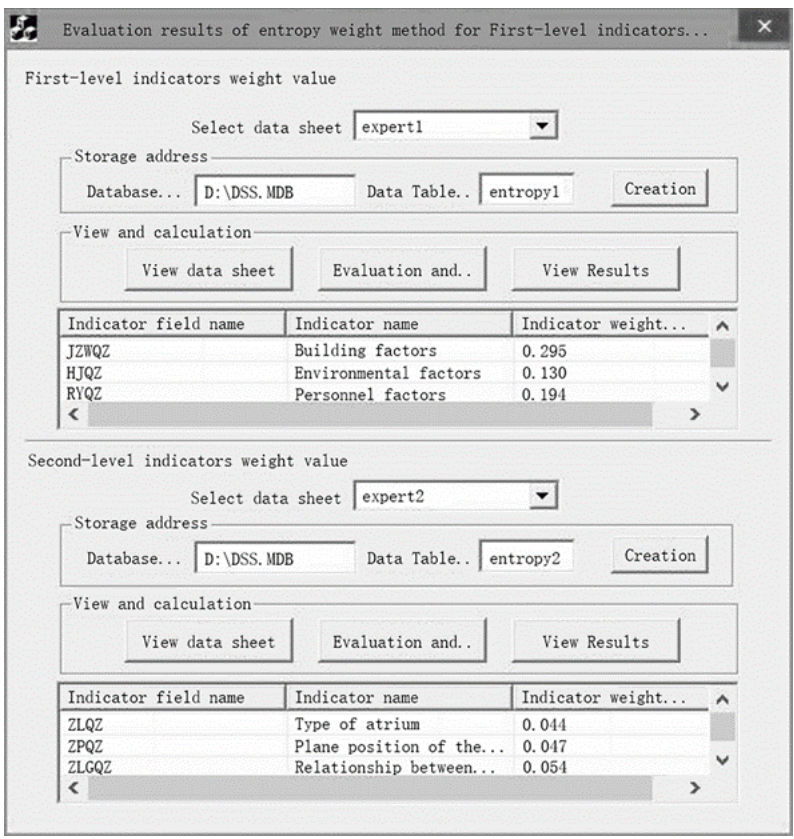

Figure 3. The result of first-level and second-level indicators weight calculation

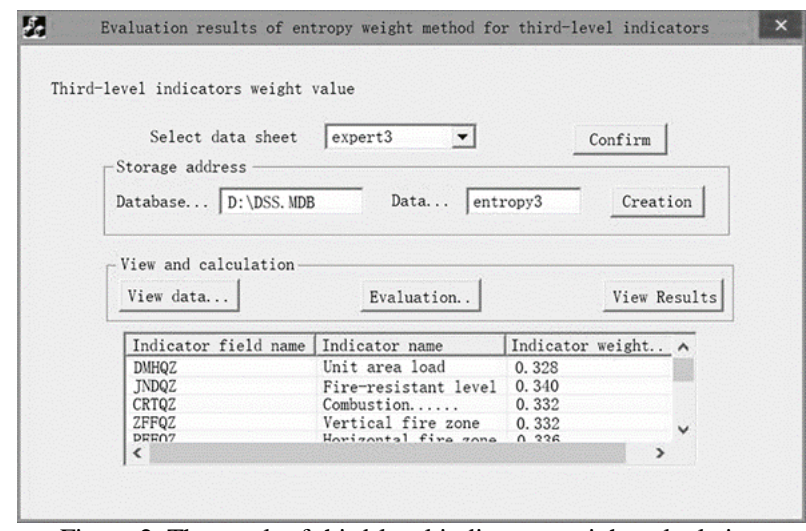

Figure 2. The result of third-level indicators weight calculation

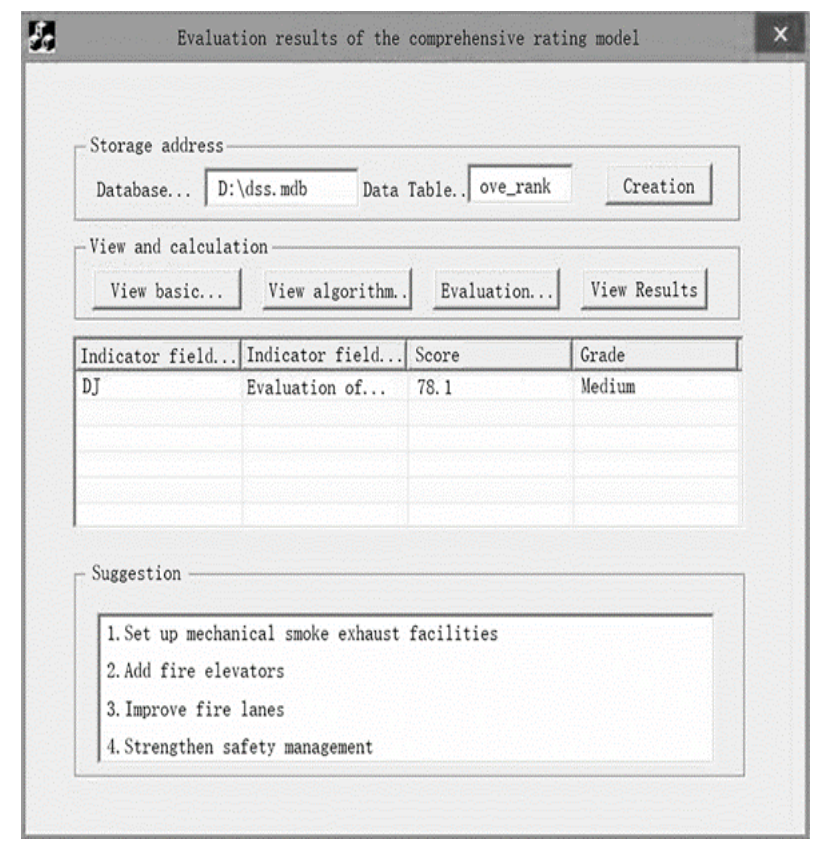

Figure 4. The evaluation results of comprehensive rating model

\section{Conclusions}

With the rapid development of China's economy and the acceleration of urbanization, large space buildings and super highrise buildings are appearing in many cities in China. It is urgent to solve the fire evacuation assessment of atriums in such complex structures. However, at present, China has not yet formed specific supporting laws, regulations, and policies, which has created a huge gap between the serious reality and the current research progress.

This paper uses a decision support system to solve this problem. Using a large-scale shopping center as a case study, it is proven that the proposed DSS of evaluation of fire evacuation performance of building atriums can scientifically and 
effectively analyze the fire evacuation status of building atriums and give improvement measures. This research has made the following contributions to alleviate the current situation in this field in China:

- Combined with the characteristics of fire evacuation of atrium buildings, related literature, and the legal norms of domestic fire evacuation, the indicator system for influencing factors of fire evacuation in building atriums was established. Through the reliability and validity analysis of the questionnaire survey, the four first-level indicators of "building factors", "environmental factors", "personnel factors", and "fire protection equipment system factors", 32 second-level indicators, and 37 third-level indicators were finally sorted out.

- The evaluation of fire evacuation performance of building atriums was innovatively combined with the decision support system. Access was used as the background database of the system, the main source code of the model library was written through Microsoft Visual $\mathrm{C}++$, and finally the evaluation results and decision-making suggestions were given by the comprehensive rating model. At the same time, through a powerful computer platform, the complex real-world decision-making problems were made more simple and efficient, helping professional managers and non-professional decision-makers make timely and informed decisions.

- Based on the research results of existing scholars and the relevant laws and regulations in China, this paper established a scientific scoring standard for the influencing factors of fire evacuation in building atriums. It also established a complete basis of and regulations for the quantification of each indicator.

- A large shopping mall was introduced as a case to show how the proposed DSS of evaluation of fire evacuation performance of building atriums calls the model data in the model library and the indicator data in the database for phase analysis and evaluation of the atriums. The DSS scored 78.1 on the shopping mall's atrium, the fire rating was medium, and suggestions were given. This paper concluded a retrospective analysis of the proposal and found out why the DSS gave these suggestions.

\section{Acknowledgments}

This research has received great support from Professor $\mathrm{Wu}$ and other scholars. The authors express their sincere gratitude for their help.

\section{References}

1. Y. Xue, L. Chang, W. Jiang, F. Xie, C. Zhang, and W. Song, "Study on Occupant Evacuation in Atrium Fire of Large Commercial Complex based on FDS Simulation," Acta Scientiarum Naturallum (Universitatis Nakaiensis), Vol. 50, No. 4, pp. 70-75, 2017

2. G. Wu, "Research on Process of Emergency Evacuation for the Major Shopping Malls and Its Surrounding," Fujian Normal University, Fuzhou, 2016

3. B. Wen, "Research and Practice on the Urban Emergency Evacuation GIS and Key Models," Information Engineering University, Zhengzhou, 2012

4. J. Zhou, "Research on Planning Support Methodology for Urban Fire Protection Planning," Wuhan University, Wuhan, 2011

5. H. Jiang and S. Zhang, "Navigation System Design of Fire Disaster Evacuation Path in Buildings based on Mobile Terminals," in Proceedings of International Conference on Computer Science \& Education, pp. 327-331, 2016

6. N. Wagner and V. Agrawal, "An Agent-based Simulation System for Concert Venue Crowd Evacuation Modeling in the Presence of a Fire Disaster," Expert Systems with Applications, Vol. 41, No. 6, pp. 2807-2815, 2014

7. M. Manley and Y. S. Kim, "Modeling Emergency Evacuation of Individuals with Disabilities (Exitus): An Agent-based Public Decision Support System," Expert Systems with Application, Vol. 39, No. 9, pp. 8300-8311, 2012

8. M. Balakhontceva, V. Karbovskii, D. Rybokonenko, and A. Boukhanovsky, "Multi-Agent Simulation of Passenger Evacuation Considering Ship Motions," Procedia Computer Science, Vol. 66, pp. 140-149, 2015

9. P. Du, J. Li, J. Peng, and H. Li, "Human Crowd Behavior Analysis and Simulation for Fire Escape," Journal of Dalian Dalian Polytechnic University, Vol. 35, No. 4, pp. 293-298, 2016

10. G. Kochilakis, D. Poursanidis, N. Chrysoulakis, V. Varella, V. Kotroni, G. Eftychidis, et al., "FLIRE DSS: A Web Tool for the Management of Floods and Wildfires in Urban and Periurban Areas," Open Geosciences, Vol. 8, No. 1, pp. 711-727, 2016

11. O. Pribyl, P. Pribyl, and T. Horak, "System for Deterministic Risk Assessment in Road Tunnels," Procedia Engineering, Vol. 192, pp. 336-341, 2017

12. S. Shahparvari, B. Abbasi, P. Chhetri, and A. Abareshi, "Vehicle Routing and Scheduling for Bushfire Emergency Evacuation," in Proceedings of IEEE International Conference on Industrial Engineering \& Engineering Management, pp. 696-700, 2015

13. P. Sarshar, J. Radianti, and J. J. Gonzalez, "Predicting Congestions in a Ship Fire Evacuation: A Dynamic Bayesian Networks Simulation," in Proceedings of International Conference on Advances in Engineering Technologies and Physical Science, pp. $247-260,2014$

14. J. Shi, Y. Lei, and X. Zhao, "Empirical Analysis of Safe Evacuation and Performance-based Evaluation in Super Commercial Complexes-A Case Study on the 38 \# Plot Project in China Resources Center in Hefei City," Safety and Environmental Engineering, Vol. 22, No. 4, pp. 142-149, 2015 
15. S. Wang, "Fire Risk Assessment of High-Rise Buildings based on Grey Relational Analysis," Journal of Safety Science and Technology, Vol. 9, No. 8, pp. 83-89, 2013

16. C. Du, "Study on Fire Risk Assessment of University based on Structure Entropy Method," Chongqing University, Chongqing, 2016

17. M. Chen, "Study on Fire Risk Assessment and Control of Subway based on the Fuzzy Theory," Huaqiao University, Fujian, 2013

18. Z. Wu, Y. Hu, M. Zhang, G. Lin, Q. Li, and Y. Huang, "Assessing Fire Risk in Historical and Cultural Blocks based on GIS: A Case Study in the Fuzhou Three Alleys and Seven Lanes," Journal of Catastrophology, Vol. 31, No. 4, pp. 205-209+223, 2016

19. Z. Feng, "Research on Fire Risk Assessment of Construction Site based on Set Pair Analysis," Xi'an University of Architecture and Technology, Xi'an, 2015

20. H. Chen, P. Yang, J. Qiu, and W. Lv, "Simulation Study on Evacuation Effect of Fire Elevator in the High-Rise Building Fire," Fire Science and Technology, Vol. 31, No. 10, pp. 1050-1053, 2012

21. X. Chen, "Fire Accident Causes and Countermeasures of Construction Site," Fire Science and Technology, Vol. 32, No. 12, pp. 1416-1418, 2013

22. S. Nai and W. Song, "Research on the Performance-based Design of Fire Protection in L-Shaped Mall Building," Safety and Environmental Engineering, Vol. 20, No. 1, pp. 126-131, 2013

23. Y. Jiang, "Research on the System of Fire Risk Assessment and Emergency Rescue Command for High-Rise Student Apartment based on SuperMap," Anhui University of Science \& Technology, Anhui, 2017

24. Y. Tian, "Building Fire Risk Assessment Guide," Chemical Industry Press, China, 2014

25. L. Zhang, H. Chen, P. Yang, and J. Qiu, "Study of Pedestrian Evacuation Effect in Different Exit Conditions," Safety and Environmental Engineering, Vol. 21, No. 3, pp. 114-120, 2014

26. Ministry of Housing and Urban-Rural Development of the People's Republic of China, "GB 50016-2014 Code for Fire Protection Design of Building," Standards Press of China (SPC), 2014

27. C. Li and L. Xin, "Research on the Evaluation Method of Reliability and Validity of Questionnaire," Chinese Journal of Health Statistics, Vol. 25, No. 5, pp. 541-544, 2008

28. S. Zhan, "Field Investigation Technique," Fudan University Press, 2003

29. S. Morton, "Management Decision Systems: Computer-based Support for Decision Making," Administrative Science Quarterly, Vol. 17, No. 1, pp. 142, 1971

30. C. M. O. Alves and M. P. Cota, "Visualization on Decision Support Systems Models: Literature Overview," in Proceedings of World Conference on Information Systems and Technologies, pp. 732-740, 2018

31. B. Klor, "Understanding the Role of Decision Support Systems in Green is Research: Literature Review and Research Agenda," in Proceedings of Pacific Asia Conference on Information Systems, Taiwan, 2016

32. S. Li, "Research on Emergency Decision Support System of Big Data Environment," Central China Normal University, Wuhan, 2016

33. L. Liang and J. Wu, "Review and Prospect on Development of Decision System," Computer Science, Vol. 43, No. 10, pp. 27-32, 2016

34. G. Xie, W. Chen, R. Liu, J. Li, and Q. Yu, "Research Literature on Public Opinion Decision Support System under the Background of Big Data," New Media and Society, Vol. 11, No. 4, pp. 155-173, 2014

35. J. Frysak, "Feedback Mechanisms for Decision Support Systems: A Literature Review," in Proceedings of World Conference on Information Systems and Technologies, pp. 481-490, 2017

36. X. Wang, "Urban Ecosystem Health Assessment based on the Analytic Hierarchy Process (AHP)-Entropy Weight Method and The Fuzzy Mathematic Method," East China Normal University, Shanghai, 2016

37. L. Wang and K. Kuang, "Fire Separation in Atrium and Human Evacuation for the Shopping," Fire Science and Technology. Vol. 31, No. 1, pp. 36-39, 2012

Weidong Wu is an associate professor and master's tutor at Southwest Petroleum University. His main research interest is the decision analysis of engineering project management.

Bohao Xu is a master's student in the School of Civil Engineering and Architecture at Southwest Petroleum University. His main research interests are risk assessment and life cycle management of engineering projects.

Qinwen Tan is a master's student in the School of Civil Engineering and Architecture at Southwest Petroleum University. Her main research interests are fabricated buildings and building information modeling.

Chuxuan Ren is a master's student in the School of Management at Sichuan University of Science \& Engineering. His main research interests are fabricated buildings and green buildings.

Tangqiao Gou is a master's student in the School of Civil Engineering and Architecture at Southwest Petroleum University. Her main research interests are sponge cities and project management. 